\title{
Entre el bufete y el laboratorio. Paul Groussac y José Ingenieros en una polémica de 1903
}

\author{
Paula Bruno* \\ Mariano Ben Plotkin**
}

Recibido el 5 de noviembre de 2017; aceptado el 15 de diciembre de 2017

\begin{abstract}
This article analyzes the transformation of the Argentine fields of intellectual production and circulation at the turn of the 20th Century from the vantage point of an apparently minor debate that took place in 1903 between the young physician José Ingenieros and the director of the National Library, Paul Groussac about the use of the term "psychiatrist". By carrying out a "dense description" of this polemical exchange as a point of departure, the article sheds light on - borrowing from Carlo Ginzburg — "the framework of deeper historical tendencies" of Argentine culture.
\end{abstract}

Key words: José Ingenieros, Paul Groussac, Cultural History, Argentina.

\section{RESUMEN}

A partir del análisis de un suceso en apariencia menor: una polémica mantenida en 1903 por el entonces joven médico José Ingenieros con el director de la Biblioteca Nacional, Paul Groussac, acerca del uso del término "psiquiatra", el artículo detecta y analiza procesos más amplios de renovación de la vida 
intelectual en la Argentina de entresiglos. Se toma este episodio como un "momento fuerte" que permita, en palabras de Carlo Ginzburg, "analizar entramados de tendencias históricas profundas".

Palabras clave: José Ingenieros, Paul Groussac, Historia cultural, Argentina.

\section{INTRODUCCIÓN}

$\mathrm{E}^{\mathrm{n}}$ n el año 1903 ocurrió en Buenos Aires un episodio aparentemente banal. Un joven médico consultó a una conocida figura de la vida cultural acerca de un tema filológico: si debía decirse "psiquiatro" o "psiquiatra" para referirse a los especialistas en enfermedades mentales. La consulta propició un intercambio polémico que se publicó en una revista vinculada a la rama médica en cuestión: Archivos de Criminología, Medicina Legal y Psiquiatría.

Quizás este acontecimiento hubiera pasado desapercibido si no fuera por el relieve de los involucrados y las proyecciones de la polémica. El futuro psiquiatra (¡o psiquiatro!) que realizaba la consulta era un joven médico nacido en Sicilia: José Ingenieros (1877-1925), una figura en vertiginoso ascenso en los mundos científico, intelectual y social argentino, y que, años más tarde, se convertiría en uno de los intelectuales más reconocidos de América Latina. El interpelado, Paul Groussac (1848-1929), por su parte, era un prestigioso intelectual nacido en Francia, quien por entonces venía ejerciendo desde hacía más de quince años (y continuaría ejerciendo hasta su muerte) la dirección de la Biblioteca Nacional. A diferencia de Ingenieros, hacia 1903 Groussac ocupaba un lugar central en el campo de la cultura argentina, campo que se hallaba aún en proceso de conformación. Se trató, pues de un intercambio desigual que confrontaba a un joven brillante y ambicioso con uno de los intelectuales más prestigiosos del cambio del siglo XIX al XX.

Al analizar este episodio, la hipótesis principal de este artículo es que aquel se trató de un evento recortado que, sin embargo, contenía significaciones sociales y culturales que lo trascendieron. Lo que estaba en juego en este episodio era nada menos que la redefinición de los sistemas de jerarquías y acumulación de capital simbólico aceptados dentro del universo cultural argentino. En el límite, lo que se dirimía era la construcción de un sistema de legitimidades en el interior de ese campo aún en proceso de consolidación. En ese contexto se podría decir que, parafraseando a Antonio Gramsci, ${ }^{1}$ por entonces la posición ocupada por Groussac - aunque se encontraba en el apogeo de su fama - representaba, sin embargo, un sistema de jerarquías que estaba en vías de convertirse en pasado y que, por esto mismo, se resistía a morir; mientras que la de Ingenieros encarnaba un futuro que todavía no 
acababa de nacer. El episodio bajo análisis constituyó un punto de intersección entrve dos trayectorias biográficas: la de Groussac, en el punto culminante de su prestigio (y como todo punto culminante, éste permitía vislumbrar el declive posterior), y la de Ingenieros, en plena ruta ascendente. Y es ese cruce de trayectorias, que destacamos como un "momento fuerte", ${ }^{2}$ el que nos permite percibir los cambios que se estaban esbozando dentro de la vida intelectual del país. Si bien, como puntualizara Pierre Bourdieu, no hay que caer en la "ilusión biográfica" de creer que una vida es una historia, ${ }^{3}$ lo cierto es que las vidas nos cuentan historias $\mathrm{y}$, al recuperar aunque sea fragmentos de ellas, podemos acceder a las historias más amplias que les otorgan, y a las cuales contribuyen a otorgarles sentidos. ${ }^{4}$

Se trata, entonces, como señalara Carlo Ginzburg, de colocar la lupa sobre un suceso particular en cuanto "campo privilegiado para analizar entramados de tendencias históricas profundas". ${ }^{5}$ De este modo, se realiza una "descripción

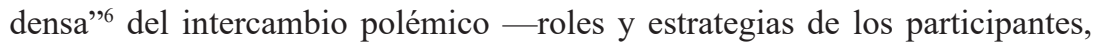
argumentos y modulaciones, el contexto y los textos- y se utiliza como una ventana que permite acceder a aspectos más generales del clima de transformación cultural de la Buenos Aires de entresiglos. ${ }^{7}$

\section{EL DEBATE Y SUS ANTECEDENTES}

La polémica de 1903 que aquí se estudia no fue la primera oportunidad en la que el joven Ingenieros interpelaba a Groussac. Ya lo había hecho en 1897, en una nota publicada en La Montaña, el periódico de tendencia socialista-anarquista, que dirigía junto con Leopoldo Lugones. Groussac había publicado en la revista La Biblioteca, fundada y dirigida por él mismo, un texto titulado "La Asociación de Mayo y el Dogma Socialista", que enfatizaba el "socialismo" de Esteban Echeverría. ${ }^{8}$ Ingenieros criticaba en La Montaña el escrito de Groussac y, en particular, su concepto de socialismo; descartaba que Echeverría pudiera considerarse socialista en el sentido científico y se refería a Groussac como alguien que "desconoce el inmenso caudal científico acumulado en los últimos

2 Pueden verse sobre estos argumentos los aportes reunidos en Hackstaff, Kupferberg y Negroni, Biography and Turning Points in Europe and America.

Bourdieu, L'illusion biographique, pp. 81-89.

Consideraciones al respecto en Bruno, Biografia e historia de los intelectuales..., pp. 19-36. Ginzburg, Apéndice. Pruebas y posibilidades, p. 436.

Geertz, La descripción densa: hacia una teoría interpretativa de la cultura, pp. 19-40.

Para un análisis detallado sobre este contexto, véase: Bruno, Pioneros culturales de la Argentina. Biografías de una época, 1860-1910 y Terán, Vida intelectual en Buenos Aires fin-de-siglo.

8 Groussac, "La Asociación de Mayo y el Dogma Socialista", La Biblioteca, año II, tomo IV (mayo de 1897), pp. 262-297. 
50 años por los verdaderos socialistas". ${ }^{9}$ Sin embargo, Ingenieros no dudaba, al mismo tiempo, en reconocer en el director de La Biblioteca a alguien que "no se arrastra" y que "tiene el doble privilegio del talento y de la independencia". En suma, lo que Ingenieros criticaba de Groussac - y veremos que utilizaría un argumento similar en el debate de 1903 - era su falta de conocimiento actualizado y especializado. Lo que admiraba, por otra parte, era el desenfado con que el francés se dirigía a figuras prestigiosas, entre las cuales se destacaba un expresidente de la nación, Bartolomé Mitre. ${ }^{10}$

Esta interpelación inicial a Groussac — que no fue respondida - puede considerarse como un prolegómeno del debate aquí tratado. Guarda con el mismo una similitud en la forma: Ingenieros, un joven estudiante que apenas frisaba los 20 años de edad, utilizaba las páginas de una publicación que él mismo dirigía, La Montaña, para intentar entablar una discusión con quien ya era una figura de gran prestigio y visibilidad. En 1903, fue en otra revista también dirigida por Ingenieros donde se publicaron tres de los documentos que constituyeron el eje público de la polémica que nos ocupa: la carta original del director de la publicación con la consulta acerca del uso del término psiquiatra; la respuesta de Groussac, bajo el título: "Psiquiatro o psiquiatra. Absolviendo una consulta"; y una nota final de Ingenieros titulada "En disidencia con Groussac". ${ }^{11}$

Ingenieros señalaba en la carta inicial que en el prólogo que Groussac había escrito, en 1895, para el libro La locura en la Argentina, de José María Ramos Mejía $^{12}$ - reconocido por Ingenieros como maestro y mentor intelectual-, el francés utilizaba la palabra "psiquiatro", aunque él (Ingenieros) se inclinaba por darle al vocablo una finalización en "a", aunque reconociendo que carecía de fundamentos firmes para hacerlo: "Escribo psiquiatra por las mismas sinrazones que me hacen escribir aeronauta, esteta, terapeuta o pediatra". ${ }^{13}$ Después de reconocer su ignorancia en temas de filología, el joven médico solicitaba su parecer al maestro. El remate de la epístola tenía un carácter

$9 \quad$ Ingenieros, "Pablo Groussac y el Socialismo", La Montaña, año I, núm. 6, 15de junio de 1897. Consultado en la edición: La Montaña. Periódico socialista revolucionario (1897). Dirigido por José Ingenieros y Leopoldo Lugones, pp. 142-146.

10 La polémica entre Groussac y Mitre tuvo lugar en 1897 y fue recopilada en Groussac, Santiago de Liniers, conde de Buenos Aires, 1753-1810.

11 Archivos de Criminología, Medicina Legal y Psiquiatría, núm. 13, vol. II (1903), pp. 6573. La forma en que es presentada la polémica es significativa porque el título general es: "Psiquiatro o psiquiatra. Absolviendo una consulta, por Paul Groussac". La carta que originó la misma está en nota al pie. Al texto de respuesta de Groussac le sigue otro de Ingenieros bajo el título de "En disidencia con Groussac".

12 Groussac, "La degeneración hereditaria". Este texto fue recogido con el mismo título en Groussac, El viaje intelectual. Impresiones de naturaleza y arte, pp. 335-372.

13 "Carta de Ingenieros a Groussac", Archivos de Criminología, Medicina Legal y Psiquiatría, núm. 13, vol. II (1903), p. 65. 
jocoso: "baste decir que me asalta la duda de si, al completar mis estudios, llegaré a ser psiquiatro o psiquiatra". ${ }^{14}$ Con este gesto, aunque la carta estaba escrita en un tono respetuoso - se manifestaba "deseoso de confirmar mi uso o modificarlo según el suyo"-, Ingenieros se permitía dudar de quien para entonces se atribuía el monopolio del buen decir. ${ }^{15}$

La respuesta de Groussac, a diferencia de la consulta de Ingenieros, mostraba desde el inicio el matiz ácido que caracterizaba los escritos polémicos de su autor. Groussac intentaba dejar claro las diferencias que lo separaban de su interlocutor. Comenzaba puntualizando que "poco suelo admitir, no mediando confianza amistosa, estas interpelaciones epistolares que, a trueque de acortar distancias, solo consultan en general la comodidad del interpelante, ahorrándole tiempo y trabajo a costa del interpelado". ${ }^{16}$ Señalaba que, aunque consideraba que no hubiera debido siquiera haberse tomado la molestia de contestar la consulta de Ingenieros, había optado por hacerlo porque detectaba en su interlocutor: "ciertos destellos intelectuales que, a través de muchas deficiencias y exuberancias juveniles, me han interesado en lo poco que de Vd. conozco". ${ }^{17}$ Con ironía, destacaba que no le resultaba posible entender cómo alguien que debía usar el vocablo en cuestión como distintivo de su identidad profesional pidiera información sobre la forma correcta de referirse al mismo. En este sentido, el francés señalaba su extrañamiento ante la actitud de Ingenieros de dejar librada "a la decisión de un aficionado su bautismo científico". 18

Luego de estos prolegómenos, Groussac desplegaba su erudición filológica y apelaba a fuentes para demostrarle a su joven interlocutor que el uso correcto del término era "psiquiatro", un neologismo al que en realidad, según reconocía, de todas maneras no le veía futuro; él, de hecho, prefería la expresión "alienista". Groussac terminaba su exposición con un "consejo" a Ingenieros acerca de cómo debía comportarse un aspirante a científico: "permítame que le diga a Ud. que su actitud es poco científica. Nada hay más opuesto al progreso de la ciencia general y del saber propio que el prejuicio. En materias que Ud. declara ignorar por completo, no puede expresar una opinión que no sea una imprudencia, y su deber absoluto es el silencio". ${ }^{19}$

$14 \quad$ Ibid.

15 En 1900 Groussac había participado del debate en torno al idioma nacional de los argentinos y había obtenido fama y respeto por su discusión con Lucien Abeille. Para información sobre el debate véase AA.VV., En torno al criollismo. La postura de Groussac puede consultarse en "A propósito de americanismos", Anales de la Biblioteca, tomo I, 1900. Reproducido en Groussac, El viaje intelectual. Impresiones de naturaleza y arte, pp. 383-426.

16 Groussac, "Psiquiatro o psiquiatra. Absolviendo una consulta", p. 65.

17 Ibid., p. 66.

$18 \quad$ Ibid., p. 66.

19 Ibid., p. 67. 
En la respuesta de Groussac es posible encontrar, además, observaciones más generales sobre un tópico recurrente en sus escritos: las limitaciones del intelecto latinoamericano:

La segunda [conclusión] expresará un consejo de amigo, y es que lleve Ud. siempre a su bufete, sea cual fuere la materia de que escriba, el mismo espíritu exento de preocupaciones y petulancias apriorísticas que supongo lleva a su clínica o laboratorio: pues el sofisma y la fatuidad del saber a medias acechan tan de cerca a este pobre intelecto sudamericano - harto combatido ya por el atavismo degenerativo — que la más severa y constante disciplina será poca para conjurar las influencias que obstan a su desarrollo. ${ }^{20}$

Aparentemente, lo que más fastidió a Groussac fue que Ingenieros se hubiera atrevido a transponer los límites del "laboratorio o la clínica" —espacio de acción de "expertos" - para acercarse al bufete —ámbito de los "intelectuales"- . ${ }^{21}$ En el sistema de jerarquías culturales sostenido por el francés, el segundo tenía primacía indiscutida sobre el primero.

Ingenieros no tardó en invertir los términos de esta ecuación. En su réplica a la respuesta de Groussac, admitía la asimetría existente entre su posición y la de su contendiente, pero inmediatamente buscaba disolverla. Comenzaba su nota diciendo que en un principio estuvo tentado a aceptar sin más la opinión de Groussac, cuya autoridad en materia de filología era indiscutible - aunque inmediatamente pasaba a cuestionarla- Y Y concluía "¿no sería una verdadera preocupación [subrayado en el original] la de aceptar sin control la opinión del Sr. Groussac, por el simple respeto que su intelectualidad nos inspira?". ${ }^{22}$

Con este gesto de desafío a la autoridad, Ingenieros resistía y replanteaba las reglas del juego sostenidas por su interlocutor. Aunque se reconocía ignorante en materia de filología, este hecho no le había impedido "investigar en los diccionarios y en los libros de los que antes han escrito". ${ }^{23}$ Esta pesquisa le permitía poner en entredicho la opinión de Groussac y las fuentes en las que éste se basaba, particularmente el Diccionario General Etimológico de la Lengua Española de Roque Barcia.

El joven médico refutó uno a uno todos los argumentos de Groussac, mostrando que las fuentes de este último estaban desactualizadas, mientras que textos más modernos (sobre todo los italianos) daban la voz "Psichiatra" como correcta. Concluía que la "a" final estaba consagrada por el uso, a pesar de que reconocía que, etimológicamente, Groussac estaba en lo correcto y correspondía la "o". Pero, según Ingenieros: "el uso es ley fundamental y

20 Groussac, "Psiquiatro o psiquatra", p. 68.

21 Para la relación entre intelectuales y expertos en el largo plazo, véase: Neiburg y Plotkin (comps.), Intelectuales y expertos. La constitución del conocimiento social en Argentina.

22 Ingenieros, "En disidencia con Groussac", p. 69.

23 Ibid., p. 68. 
puede violar las reglas etimológicas". ${ }^{24}$ Ingenieros desafiaba la autoridad de Groussac, y al hacerlo cuestionaba todo el sistema de jerarquías en el que se basaba esta última:

Extraña al Sr. Groussac nuestra consulta y juzga, en un médico-alienista, 'sorprendente que no sepa todavía, a qué atenerse y deje á la decisión de un aficionado su bautismo científico...'. Es de sabiduría vulgar que no son los bautismos una función propia de los médicos, sinó de los sacerdotes; así se explica que apeláramos al Sr. Groussac, que es tenido por tal en estos enjuagues del bien decir y de la crítica [...] Es incierto, pues, que dejemos á la decisión de un aficionado el presunto bautismo científico; acudimos á quien es, notoriamente, para caso como éste, una autoridad. ${ }^{25}$

Ingenieros usaba así, argumentos de especialista y negaba ese estatuto a Groussac, quien era desplazado a la categoría de sacerdote, capaz de "bautizar", pero sin las herramientas adecuadas para sostener el debate. De este modo concluía el debate publicado en Archivos. Como se verá más abajo, antecedió a éste un intercambio epistolar que permaneció inédito y que permite acceder a otras dimensiones de la polémica.

\section{LOS CONTENDIENTES: VIDA E HISTORIAS}

Hacia el momento en que se desarrolló la polémica, las trayectorias de José Ingenieros y Paul Groussac eran contrastantes. Nacido en Francia en 1848, Groussac vivió en Argentina desde 1866 hasta su muerte en 1929. ${ }^{26}$ Durante su estadía en el país, se desempeñó como docente, director e inspector de escuelas, periodista y director de diarios, tanto en Tucumán (donde residió más de una década) como en Buenos Aires. Finalmente, en 1885 fue nombrado director de la Biblioteca Nacional, cargo que mantuvo por 44 años, y que lo posicionó en un lugar de alta visibilidad en la vida intelectual del país.

Groussac no ostentaba credenciales académicas de prestigio. Llegó a Buenos Aires a los 18 años y su educación formal había concluido en el liceo de Toulouse. Se trataba, por lo tanto, de un autodidacta formado a base de —según sus propias palabras_—, "infatigables lecturas, llevadas con más ardor que método" realizadas mientras circulaba por el país y hechas posible, gracias a que "la erupción educativa de Sarmiento había derramado a millares los cajones de libros de toda laya e índole por el territorio argentino". ${ }^{27}$ Más tarde,

Ibid., p. 73.

Ibid., p. 70.

Sobre Paul Groussac pueden consultarse: Bruno, Paul Groussac. Un estratega intelectual.

Groussac, "Alphonse Daudet", en La Biblioteca, tomo VI, 1897. Reproducido en Bruno (ed.), Travesías intelectuales de Paul Groussac, p. 272. 
su puesto en la Biblioteca le permitió un contacto asiduo con las novedades del viejo mundo. Desde allí propulsó publicaciones destacadas, como La Biblioteca (1896-1898) y Anales de la Biblioteca (1900-1915); escribió, además, una gran cantidad de obras históricas, ficciones y ensayos. ${ }^{28}$

Como funcionario del Estado - aunque siempre con posturas críticas respecto de los gobiernos de turno, la vida política en general y sus dinámicas-, la posición de Groussac a cargo de la Biblioteca le permitió convertirse en un intelectual de tiempo completo consolidándose como un referente intelectual frente a sus pares. Encarnó la figura del prescriptor y llegó a ocupar, como señala la fórmula propuesta por Ricardo Piglia, "el papel de árbitro, de juez y verdadero dictador cultural". ${ }^{29}$

Hacia 1903, Groussac ya contaba con una fama de implacable polemista en el ámbito cultural argentino. ${ }^{30}$ Rubén Darío se refería a su aura como la de "el hombre que devora vivas las gentes", "el descuartizador", y "el condestable de la crueldad". 31

Las páginas de La Biblioteca se convirtieron en escenario de virulentas controversias que tuvieron como infatigable protagonista a su director. ${ }^{32}$ Una de estas controversias, sostenida con Norberto Piñero en 1898, quien por entonces ocupaba un importante cargo diplomático, determinó el cierre de la revista. El tono ácido que mantuvo Groussac resultó inaceptable para sectores del gobierno decididos a defender a Piñero y el francés fue presionado para cesar la publicación. En la nota en que daba cuenta del final de la misma, el director de la Biblioteca Nacional hacía gala de su independencia intelectual y caracterizaba su empresa de la siguiente forma:

Por mi parte tenía la elección entre explotar industrialmente el filón del presupuesto, imprimiendo á doscientos ejemplares, y en mal papel, vagos cuadernos de documentos inéditos, hasta formar cada año un tomo de 300 á 400 páginas, que habría sometido al visto bueno oficial y nadie hubiese leído; ó acometer de mi cuenta y riesgo una empresa civilizadora [subrayado en el original] intentando fundar una gran revista mensual, no inferior á las europeas, amplia en sus manifestaciones, libérrima en sus tendencias, que estimulase a los

Véase: Canter, Contribución a la bibliografía de Paul Groussac, 1930.

Piglia, Respiración artificial, p. 114.

En 1903, el dibujante español José M. Cao, publicó en Caras y Caretas, una caricatura en la que lo caracterizaba como un gallo arrogante. Debajo de la imagen se lee la siguiente rima: "Como tiene un espolón/de sólida erudición, /le alza el gallo y le pelea/á cualquier otro, aunque sea/el gallo de la Pasión".

Darío, “El triunfo del Calibán”, El Tiempo, 20 de mayo de 1898, reproducido con notas de Carlos Jáuregui, Revista Iberoamericana, vol. 44, núm. 184-185 (1998), versión electrónica. Sobre la revista puede consultarse: Bruno, "Paul Groussac y La Biblioteca (1896-1898)": Hispamérica. Revista de literatura, año 32, núm. 94 (2003), pp. 87-94. 
talentos conocidos y suscitase á los ignorados, hasta reflejar honrosamente el intelecto argentino en sus varias aplicaciones. ${ }^{33}$

Sin embargo, Groussac continuó manteniendo ácidas polémicas y, hacia el cambio de siglo, comenzó a extender sus críticas hacia otras latitudes de la cartografía intelectual hispanoamericana. Así, por ejemplo, en 1902, en las páginas de Anales de la Biblioteca, planteó una serie de críticas a una edición de Descripción del Perú por Tadeo Haenke preparada por el Director de la Biblioteca Nacional de Perú, Ricardo Palma. Groussac demostró con gran cantidad de pruebas el carácter apócrifo del documento atribuido al naturalista. ${ }^{34} \mathrm{Al}$ año siguiente, intentó mantener una polémica con Marcelino Menéndez Pelayo; sin embargo, éste no le dio lugar y lo dejó sin espacio para la réplica al criticar su (de Groussac) Une énigme littéraire. Le 'Don Quichotte' d'Avellaneda. Menéndez Pelayo puso en evidencia las falencias existentes en las interpretaciones del francés; entre ellas destacó el error de haberle atribuido la autoría del Quijote de Avellaneda al valenciano Juan José Martí, quien había muerto antes de la publicación del Quijote original. ${ }^{35} \mathrm{El}$ silencio de Groussac ante estas devastadoras críticas fue elocuente y mostró que su posición como referente intelectual en Argentina tal vez pudiera extenderse a otros países latinoamericanos, pero decididamente no a Europa. En el sistema de jerarquías intelectuales que se estaba conformando en América Latina, Groussac ocupaba un lugar al que no podía aspirar cuando se trataba de Europa, a pesar de su propio origen europeo.

La trayectoria de Ingenieros hasta el cambio de siglo había sido muy diferente. ${ }^{36}$ Nacido en Sicilia en 1877, su padre (coetáneo de Groussac) era un comerciante y periodista vinculado a la Asociación Internacional de Trabajadores y con fuertes lazos en la masonería, donde había alcanzado el grado 33 del Rito Escocés Antiguo y Aceptado. ${ }^{37}$ En Buenos Aires, Salvatore

33 Groussac, "La desaparición de La Biblioteca": La Biblioteca, tomo VIII (1898), p. 247.

34 El artículo que Groussac escribió sobre Haenke se titula "Noticias de vida y trabajos científicos de Tadeo Haenke", Anales de la Biblioteca, tomo I, 1900. La crítica al trabajo de Ricardo Palma se encuentra en "Tropezones editoriales, una supuesta 'Descripción del Perú,", Anales de la Biblioteca, tomo II (1902). Ambos artículos fueron recopilados en Paul Groussac, Crítica literaria, pp. 369-397.

35 Este debate está detalladamente presentado en Oria, "La polémica de Menéndez y Pelayo con Groussac. Sobre el "Quijote” de Avellaneda”, Humanidades, tomo XXIV (1934), pp. 3-72.

36 Sobre la vida de Ingenieros véase Bagú, Vida ejemplar de José Ingenieros; Ponce, José Ingenieros: su vida y su obra. Educación y lucha de clases. Sobre las ideas de Ingenieros, puede consultarse Terán, José Ingenieros, antiimperialismo y nación, y del mismo autor: José Ingenieros, pensar la nación.

37 Salvatore Ingegnieros llegó a América del Sur con recomendaciones emitidas por la Grande Oriente della Massoneria in Italia, fechada en Roma el 27 de agosto de 1880; y con una carta manuscrita de Giuseppe Garibaldi, fechada el 11 de agosto del mismo año, recomendándolo a "nostri fratelli de Montevideo". Véase Archivo Ingenieros, CEDINCI, A.6.3 SAA/8-4/101 DOc 10, y A.6.3 SAA/84/10.1 Doc. 20. 
Ingegnieros (tal el apellido original que José españolizaría recién en la década de 1910) fundó y dirigió por años la Revista Masónica e incorporó a su hijo como lowatón en la logia Unione Italiana 1 de la cual ocupaba el cargo de venerable, cuando aquél contaba apenas con ocho años de edad..$^{38}$ Ingenieros fue iniciado formalmente en la logia en 1898 y seguiría vinculado a la masonería hasta el final de su vida.

Al igual que otras familias de inmigrantes, la de Ingenieros consideraba que la educación constituía una vía privilegiada de ascenso social en la Argentina de entonces. Después de pasar por el que luego sería el Colegio Nacional de Buenos Aires - espacio de socialización por excelencia para los hijos de la élite local-, el joven Ingenieros ingresó en la recientemente reformada Facultad de Medicina donde se recibió de farmacéutico en 1897 y de médico pocos años después. Ya para ese momento, no había pasado desapercibido en ninguno de los ámbitos en los que le había tocado actuar, aunque, contra lo que él mismo y otros sostuvieron, su performance académica no parece haber sido particularmente destacada. ${ }^{39}$ Con apenas 18 años de edad, se acercó a Juan B. Justo - líder del Partido Socialista argentino- y fue uno de los miembros fundadores del Centro Universitario Socialista, y luego el primer secretario del Partido Socialista. Dentro del partido se destacó por sus dotes de orador y sus dificultades para someterse a la disciplina partidaria, lo que le costó algunas sanciones. En 1897, junto con Leopoldo Lugones — ambos eran los jóvenes líderes del "ala izquierda" del partido, con simpatías cercanas al anarquismo - fundó el efímero y ya mencionado periódico La Montaña, que tuvo una proyección más allá de las fronteras argentinas. Para entonces, el joven Ingenieros había obtenido una reputación dentro de los círculos socialistas, no solamente en Argentina, sino también en Chile y Uruguay, aunque muy pronto abandonó la militancia activa y, más tarde, su afiliación al partido para dedicarse de lleno a la ciencia.

Luego de un giro que lo llevó a convertirse en colaborador estrecho del dos veces ex presidente Julio A. Roca durante la estadía que ambos compartieron en Europa entre 1905 y 1906, Ingenieros, a poco de producirse la Revolución rusa, se convirtió en un paladín de la misma en Buenos Aires $\mathrm{y}$, más tarde, en un promotor de la unidad latinoamericana y defensor de la Revolución mexicana. ${ }^{40}$ "adoptados" por una logia en una especie de bautismo masónico

39 Su boletín de calificaciones correspondiente al año 1888 del Colegio Nacional de la Capital (que se encuentra sin clasificar en el Archivo Ingenieros, CEDINCI) muestra un promedio de notas de 3,6/10 y un registro de "Pésima" en lo que respecta a conducta. Por otro lado, su certificado analítico de materias de la Facultad de Medicina que se encuentra en el archivo de la misma, registra a lo largo de la carrera un promedio de calificaciones de 6,74/10.

40 Véase: Pita González, La Unión Latinoamericana y el Boletín Renovación: Redes intelectuales y revistas culturales en la década de 1920. 
Lector voraz $-\mathrm{y}$ a la vez desordenado- y poseedor de amplísimas inquietudes intelectuales, hacia los 20 años de edad Ingenieros se había familiarizado con la literatura no sólo científica, sino además política y social producida en Europa. Por otro lado, junto con sus mentores José María Ramos Mejía y Francisco de Veyga, se convirtió en uno de los propulsores locales de la criminología positiva. Así, desde muy temprano se vinculó a la revista Criminalogía Moderna, dirigida por el exiliado anarquista italiano Pietro Gori, publicación que fue muy activa en la difusión de las nuevas corrientes criminológicas. Más tarde, el propio Ingenieros ocuparía un lugar central en ese campo en formación desde la dirección de los mencionados Archivos.

Al mismo tiempo, frecuentaba círculos literarios, en particular el que funcionaba en torno a Rubén Darío con quien formó, junto con otros, una sociedad entre literaria y lúdica llamada La Syringa. Ingenieros era reconocido como una especie de niño prodigio, cuya brillantez intelectual deslumbraba, y como un enfant terrible en círculos sociales a los que pudo acceder en buena medida gracias a su capital cultural, su inteligencia y las dotes histriónicas de su personalidad que desde temprano fueron generando un "estilo Ingenieros" que él sabría cultivar y explotar en su favor. Con estos elementos, intentaba - y hasta cierto punto lo logró- compensar su escaso capital social. ${ }^{41}$

Por lo tanto, para el momento en que tuvo lugar la polémica con Groussac, Ingenieros, aunque era muy joven, ya era un personaje conocido en círculos científicos y culturales y comenzaba a proyectarse hacia el extranjero. Esto se puso en evidencia de manera clara dos años más tarde, durante su primer viaje a Europa, que tuvo lugar cuando fue enviado como representante de la Argentina al V Congreso Internacional de Psicología de Roma, en 1905. En esa oportunidad, logró entablar amistades con algunos de los intelectuales y científicos más prestigiosos del momento.

En 1903, el mismo año de la polémica con Groussac, Ingenieros ganó, además, un premio otorgado por la Academia Nacional de Medicina por su libro sobre la simulación de la locura, versión considerablemente revisada y muy ampliada de su tesis doctoral. El libro sería casi inmediatamente traducido al italiano y luego a otros idiomas y elogiado por personajes de fama internacional tales como Max Nordau y Henry Maudsley. ${ }^{42}$

Se podría pensar que, de manera semejante a Groussac, pero partiendo de un lugar muy diferente, Ingenieros también puso en práctica estrategias muy precisas para construir un personaje y una imagen que le permitiera

41 Sobre las élites en el cambio de siglo puede consultarse: Losada, La alta sociedad en la Buenos Aires de la Belle Époque. Sociabilidad, estilos de vida e identidades.

42 Ingenieros, Simulación de la locura ante la sociología criminal y la clínica psiquiátrica, precedida por un estudio sobre la Simulación en la lucha por la vida en el orden biológico y social. 
sobreponerse a sus hándicaps sociales de origen que lo obligaron, entre otras cosas, a mantener a sus padres con su trabajo desde la edad de 18 años. En la correspondencia mantenida con su padre — que retornaría a Italia en 1904-, se explicitaban desde posibles estrategias matrimoniales (llegando al punto de considerarse en condiciones de aspirar a la hija menor del general Roca), hasta sus formas particulares de entablar relaciones sociales e intelectuales nacionales e internacionales, así como también una difusión muy bien programada de su obra científica que crecía a ritmo exponencial. ${ }^{43}$

Todo ello parecía destinado a permitir a Ingenieros posicionarse lo más alto posible en la jerarquía social que estaba en vías de reformulación. ${ }^{44}$ Sin embargo, esta correspondencia también ponía en evidencia no sólo las inseguridades del joven Ingenieros respecto de la fragilidad de su posición social, sino también los límites de lo posible en lo que respecta a las posibilidades de reconversión de capital intelectual en capital social.

En paralelo, desde muy joven, Ingenieros se preocupó por conseguircargos en la rápidamente creciente burocracia técnica estatal que se estaba desarrollando, así como también dentro de los mecanismos de institucionalización de la medicina y la criminología. Sin embargo, y a pesar de su prestigio ascendente, no logró ocupar cargos de relevancia institucional, aunque su nombre sonaría para la dirección del flamante Departamento Nacional de Trabajo en 1907. Tampoco fue totalmente exitoso en obtener el reconocimiento que él esperaba entre sus pares: a pesar de sus ingentes esfuerzos no logró ser admitido en la Academia Nacional de Medicina. Finalmente, en 1911 abandonó el país por segunda vez cuando el presidente Roque Sáenz Peña vetó su nombre para ocupar la cátedra de medicina legal dejada vacante por Francisco de Veyga.

\section{Polémicas y polemistas}

La polémica que Ingenieros entabló con Groussac en 1903 puede ser entendida dentro de un entramado de estrategias destinadas a hacer posible su propia promoción dentro de un espacio intelectual en proceso de especialización. Para comienzos del siglo xx, Groussac ya había mantenido debates con personajes de la estatura de Bartolomé Mitre, Miguel Cané, Calixto Oyuela, Norberto Piñero, Eduardo Schiaffino y Ricardo Palma, entre otros. En el mismo contexto, Ingenieros también se revelaba como feroz polemista; de hecho, a

43 Para más detalles, véase: Plotkin, "José Ingenieros, El Hombre Mediocre, and the Possibilities and limits of Social Integration in Turn of the Century Argentina", William Beezley (ed.), Oxford Research Encyclopedia of Latin American History. Disponible en $<\mathrm{http}$ //latinamericanhistory.oxfordre.com/view/10.1093/acrefore/9780199366439.001. 0001/acrefore-9780199366439-e-346?rskey=F5Xsiz\&result=5> .

44 Sobre estos procesos pueden verse: Plotkin y Zimmermann (comps.), Los saberes de Estado y Plotkin y Zimmermann (comps.), Las prácticas del Estado. 
lo largo de su vida eligió cuidadosamente a sus contrincantes al tiempo que diseñaba tácticas que le permitieran posicionarse favorablemente. De este modo, la posibilidad de establecer una polémica de pares con Groussac era una forma de acumulación de prestigio. Ya desde principios del siglo xx Ingenieros ventilaba sus conflictos en la prensa mostrando una lengua afilada que más de una vez lo llevó cerca de batirse a duelo.

Por ejemplo, un año antes de la polémica de 1903, había mantenido otra con el diplomático y escritor uruguayo Armando Vasseur, quien escribía con el seudónimo de "Américo Llanos", con motivo de un comentario de este último a un artículo publicado previamente por Ingenieros en un periódico socialista. La nota de Ingenieros se publicó en el diario La Tribuna Popular de Montevideo, el 5 de mayo de 1902 como una carta al director. ${ }^{45}$ Ingenieros no solamente se refería a su contendiente en femenino (Vasseur era homosexual), sino que, además, lo descalificaba de una manera similar a la que utilizaba Groussac con sus contrincantes. Así, se preguntaba Ingenieros:

¿Pretenderá [Vasseur] polemizar conmigo? No sería extraño. Recuerdo que entre los quince y los diez y ocho años escribí tres artículos atacando duramente a Spencer a Brunetière y a Max Nordau con la esperanza de que me hicieran el honor de la polémica. Pueril esperanza! Que creo reconocer ahora en la conducta de esta (sic) joven que frisa ya los 24 de su vida estéril y sin lustre.

Ingenieros sostenía que sólo la "envidia ambiciosa" de Vasseur le "impide ver la distancia que nos separa", y en este sentido, aunque pareciera colocarse en una posición similar a la que Groussac asumiría frente a él: no reconocer a su polemista como un igual, existían diferencias significativas entre el siciliano y el francés.

Si Ingenieros comparaba la distancia que supuestamente lo separaba de Vasseur con la que lo había apartado a él mismo de personajes tan diferentes como Spencer, Brunetière o Nordau cuando todavía no había salido totalmente de la adolescencia, esto respondía en parte a que su nombre por sí sólo (el de Ingenieros) no era suficiente para marcarla por sí mismo. En 1903, luego de una trayectoria que parecía haber llegado a su cumbre, Groussac no requería de comparaciones de esta clase porque él mismo era portador de un nombre ampliamente reconocido, mientras que Ingenieros aún no lo era. Y es por eso que el siciliano se veía obligado a recordarle a Vasseur que "recién en los últimos años he visto mi opinión citada con respeto y elogio en publicaciones europeas de Ferri, Aquiles Loria, Deville, Morselli, Unamuno, Lombroso, Lacassagne, Tarde, Gambarotta, VIazi, Antonini, Hamon, Penta, Zuccarelli, Hargemberg,

45 José Ingenieros, carta dirigida al director de La Tribuna Popular, Montevideo, 5 de mayo de 1902. Puede consultarse copia de la misma en el Archivo Ingenieros, CEDINCI: A.6.2 SAA/8.4/9.1 Doc. 47. La nota de Vasseur se había publicado en La Rebelión de Montevideo, el 31 de agosto de 1902 bajo el título de "Esgrima literaria". 
Bancerl, Feriani, etc.; varios me han hecho el honor de la polémica". ${ }^{46}$ Quedaba claro que Ingenieros intentaba suplir con esta abultada (y heterogénea) lista de personajes ilustres con los que supuestamente interactuaba su propia escasez de capital de reconocimiento.

Por otra parte, y esto es aún más significativo, Ingenieros utilizaba con Vasseur líneas argumentales de la misma naturaleza que utilizaría luego con Groussac. Es que Vasseur, perteneciente a una familia de la élite uruguaya, no era tampoco en términos sociales un par de Ingenieros. Es así que Ingenieros le recordaba a su interlocutor que la posición desde la que se autorizaba para denostarlo se basaba en dos elementos fundamentales de los que carecía el uruguayo: conocimiento experto y trabajo duro. Ingenieros reconocía:

Mis palabras son harto duras y que ciertas verdades no deben hacerse públicas; pero tampoco es justo que quien ocupa una posición científica y social, conquistada con propio esfuerzo y no por favoritismo deshonesto, quede librado a la ventura de cualquier alienado metido a panfletista. ${ }^{47}$

Y más adelante: "Tengo una reputación científica, que solo se debe a mis trabajos de sociología y psiquiatría; no me es posible oír sino a mis iguales".

Puede verse en este intercambio (aunque sólo tengamos acceso al "lado de Ingenieros") la puesta en evidencia de una estrategia que incluía la proyección de su propia autoimagen. Si Ingenieros consideraba a su contendiente como indigno de su respuesta (que de cualquier manera daba y de modo público), esto no se debía a la posición social del siciliano que no podía competir en ese terreno con Vasseur y mucho menos luego con Groussac, sino a su carácter de self-made scientist. Conocimiento y esfuerzo estarían en la base de la legitimidad de la posición que Ingenieros se construía para sí y esto permanecería constante a lo largo de su vida. Sin duda, entrar en polémica con alguien consagrado constituía una fuente de prestigio y esto es algo que Ingenieros tendría bien claro a lo largo de su trayectoria como se puso de manifiesto en el episodio con Groussac.

De este modo, si a los 18 años Ingenieros había intentado sin éxito polemizar con Herbert Spencer o Max Nordau, a los 25 había logrado hacerlo, al moderar sus expectativas, con Groussac, quien para 1903, era un referente indiscutido de la cultura argentina. Ingenieros, por su parte, estaba en vías de convertirse en un científico de cierto prestigio, pero tenía todavía un camino por delante para recorrer. Fue en ese contexto, como se señaló, que Groussac parecía molesto ante la intención de "ascenso" de Ingenieros desde su condición de "experto" (laboratorio y clínica) a la de "intelectual" (bufete). Sin embargo, lo que realmente estaba en juego era la definición de mecanismos de prestigio y legitimidad dentro del mundo de los intelectuales.

46 Ingenieros, carta al director de La Tribuna Popular, cit.

47 Ibídem. 


\section{SOCIABILIDADES Y EMPRESAS EDITORIALES}

Las diferencias entre las trayectorias de Ingenieros y Groussac se pueden observar también en los ámbitos de sociabilidad en los que se encontraban insertos y en el tipo de empresas editoriales que dirigía cada uno de ellos en el contexto del debate. En el cambio del siglo XIX al Xx, las formas de sociabilidad cultural se estaban reconfigurando en Buenos Aires. Aparte de los espacios de intercambio más puramente sociales, tales como el Club de Progreso y otros, después de la caída de Juan Manuel de Rosas se produjo una verdadera explosión en la vida asociativa de la ciudad. ${ }^{48}$ Durante la segunda mitad del siglo se fueron conformando círculos y asociaciones con un perfil netamente "disciplinar" o "profesional", tales como la Asociación Médica Bonaerense (inaugurada en 1860) o el Instituto Geográfico Argentino (fundado en 1879). Empero, al mismo tiempo hicieron su aparición otras formas más o menos institucionalizadas de sociabilidad cultural que podían reunir a figuras muy diversas en su interior, tales como el Círculo Literario, el Círculo Científico, la Academia Argentina de Ciencias y Letras o la Sociedad Científica Argentina (creada en 1872). La mayoría de esos grupos culturales participaba de un consenso alrededor de la idea de que la república letrada debía constituir el vector del progreso intelectual del país y, por lo tanto, convenía convocar a hombres con intereses diversos para sostener proyectos colectivos. ${ }^{49}$ El escenario, entonces, configurado entre fines de siglo y el momento del Centenario muestra, por lo tanto, una coexistencia de diversas formas de sociabilidad de intelectuales que todavía, además, incluían como espacio privilegiado a las logias masónicas.

La masonería constituía un espacio particularmente significativo porque, aunque las logias estaban divididas tanto por su orientación ideológica como por los sectores sociales y origen étnico entre los que reclutaban a sus miembros, conformaban, sin embargo, un sistema bastante poroso de interacción e intercambio social. ${ }^{50}$ Además, muchas de ellas compartían el templo (aún hoy existente) de la calle Cangallo, Juan Domingo Perón. ${ }^{51}$ Era el espacio de la masonería el que tornaba posible e incluso probable que "un inmigrante venido en tercera clase" como Ingenieros solía caracterizarse a sí mismo en privado,

48 Sobre las sociabilidades intelectuales puede verse: Bruno (directora), Sociabilidades y vida cultural. Buenos Aires, 1860-1930.

49 Véase Bruno, "La vida letrada porteña entre 1860 y el fin-de-siglo. Coordenadas para un mapa de la élite intelectual”, Anuario IEHS, núm. 24, 2009, pp. 338-369.

50 Véase: González Bernaldo de Quirós, Civilidad y politica en los orígenes de la Nación Argentina. Las sociabilidades en Buenos Aires, 1829-1862.

51 Sobre el desarrollo de la masonería en América Latina, véase la tesis doctoral de Dévrig Mòlles, Triangle atlantique et triangle latin. L'Amérique Latine et le système-monde maçonnique (1717-1921), Université de Strasbourg, 2012. 
se codeara con Joaquín V. González, con el hijo o el hermano del general Roca, o incluso con Bartolomé Mitre.

Los múltiples ámbitos de sociabilidad no eran excluyentes entre sí: era usual que los mismos hombres públicos participaran en unas y otras instancias, siendo, quizás, la masonería, la que agrupaba a la mayoría de ellos. Leopoldo Lugones e Ingenieros fueron figuras relevantes en los encuentros entre figuras del anarquismo y el socialismo hacia finales del siglo XIX, y participaron, al mismo tiempo, en las publicaciones de las sociedades teosóficas y espiritistas $\mathrm{y}$, desde luego, en asociaciones de índole literaria. Ambos fueron prominentes masones, Lugones llegó a ser Pro Gran Maestre de la Gran Logia de la Argentina en 1906 y $1907 .{ }^{52}$ Se podría decir que Ingenieros hizo uso de todos los espacios de sociabilidad (y socialización) que tuvo a su disposición desde muy joven: desde el Colegio Nacional en el cual se codeaba con los hijos de miembros de la élite social e intelectual, la Facultad de Medicina, pasando por las ligas masónicas, hasta el Partido Socialista y los círculos literarios y científicos. Ingenieros fue el producto de estos espacios de sociabilidad y actor privilegiado de otros que él mismo contribuiría a constituir a lo largo de su trayectoria: revistas tales como Archivos o más adelante Revista de Filosofia, o empresas editoriales de largo aliento como la colección "La cultura argentina".

Si Ingenieros fue a la vez producto y propulsor de entidades asociativas, bien distinto fue el caso de Groussac, quien parece haberse mantenido al margen de las instancias de sociabilidad. A lo largo de su extensa trayectoria no participó activamente de ningún espacio colectivo, excepto en los generados por él mismo desde su cargo en la Biblioteca Nacional. Ni siquiera se acercó a la masonería, constituyendo, de esta manera, una rara avis entre los miembros de la élite intelectual. Groussac asumía que era su propio prestigio intelectual el que le otorgaba legitimidad. Para ello, se había servido de las páginas de La Biblioteca (1896-1898) y de los Anales de la Biblioteca (1900-1915) para publicar textos de destacados hombres de cultura de la época, mostrar y comentar novedades estéticas, criticar trabajos de los contemporáneos, y trazar los límites entre lo que consideraba aceptable o rechazable.

$\mathrm{Si}$ estas publicaciones oficiaban como vidrieras para la producción intelectual de Groussac, podría decirse algo parecido de respecto de la trayectoria de Ingenieros. La revista fue uno de los pilares a partir de los cuales Ingenieros contribuyó de manera simultánea a construir un campo profesional y a forjar para sí un lugar central dentro del mismo. Aunque desde una posición distinta a la de Groussac, Ingenieros hizo de su revista una vidriera para exponer sus ideas (varios de sus libros, incluyendo El hombre mediocre se originaron en artículos previamente publicados allí). ${ }^{53}$ La publicación se convirtió en un

52 Véase: Lappas, La masonería argentina a través de sus hombres, p. 265.

53 Sobre esta cuestión puede consultarse: Pita González y Bruno, "Definiendo su propia emoción. Una lectura de El hombre mediocre de José Ingenieros", pp. 189-229. 
órgano de consagración profesional y en un espacio donde su director dirimía sus diferencias con otros. Aunque la revista se creó como una empresa privada, una vez que Ingenieros fuera nombrado director del Instituto de Criminología de la Penitenciaría Nacional, Archivos pasó a ser su publicación oficial. Ingenieros construyó a partir de ella una red de intercambios y circulación de ideas a nivel latinoamericano y, en menor medida, europeo. Archivos fue uno de los intentos más tempranos llevados a cabo en la región de constituir una revista profesional con reconocimiento internacional sobre temas vinculados a la psiquiatría y a la criminología. Ésta fue la plataforma que Ingenieros eligió para ventilar su polémica con Groussac.

En suma, aunque con cierto aire de familia a la hora de administrar las publicaciones que dirigieron, las diferencias de edad, de trayectorias y de circuitos por los que circulaban los contendientes no hacía obvia la posibilidad de un cruce entre ellos, $y$, de hecho, es muy probable que ni siquiera se hubieran conocido personalmente para esa fecha. Sin embargo, no resulta sorprendente que Ingenieros — quien inició el acercamiento- conociera perfectamente la fama de Groussac. Menos claro resulta, sin embargo, la forma en la que este último se había puesto en contacto con los "destellos intelectuales" que decía conocer de Ingenieros. Quizás conocía algunas publicaciones de Ingenieros y supiera de él a partir de referencias de Ramos Mejía, cuyo libro, recordemos, había prologado y a quien Ingenieros consideraba como uno de sus maestros.

Pese a los diferentes posicionamientos, sin embargo, Groussac e Ingenieros establecieron relaciones personales con un elenco similar de nombres, entre los que podemos mencionar a Bartolomé Mitre, Joaquín V. González, Miguel Cané, Rubén Darío, Juan Agustín García, Lucio Vicente López, Leopoldo Lugones, Ernesto Quesada, José María Ramos Mejía, Manuel Gálvez, Alfredo Bianchi, Roberto Giusti, entre otros. De este modo, a pesar de las distancias, puede señalarse que ambos polemistas compartían un espacio cultural que, a fin de cuentas, era relativamente estrecho. Este hecho fue puesto en evidencia, por ejemplo, por la revista Caras y Caretas, que en 1904 publicó una nota titulada "Gente de Letras". En la misma se presentaban semblanzas de Paul Groussac, José María Ramos Mejía y José Ingegnieros (todavía utilizaba su apellido original) caracterizado este último como "el más joven de los escritores científicos argentinos". Mientras que lo que el articulista destacaba de Groussac era "su bella reputación de varón docto y tranquilo" así como la acidez de su pluma; destacaba de Ingenieros que "a pesar de su levita, de sus cuellos, de su galera, y del robe de chambre... tiene talento, un talento fresco, entusiasta". ${ }^{54}$ Es decir, a pesar de poner a ambos nombres en la misma nota, quedaban claras las diferencias de posicionamientos en el mundo cultural. Groussac era ya acto y prestigio. Ingenieros era potencia y apariencia.

54 “Gente de Letras", Caras y Caretas, 18 de junio de 1904, p. 32. 


\section{INTERCAMBIO EPISTOLAR TRUNCO}

La polémica no se limitó a su dimensión impresa. Las notas publicadas en Archivos fueron precedidas por un intercambio que no estaba destinado a ver la luz pública. ${ }^{55} \mathrm{La}$ carta con la que Ingenieros realizó la consulta inicial era originalmente privada. A su pedido, Groussac accedió en un principio a que su respuesta fuera publicada, siempre que se le permitiera realizar correcciones previas para cambiar "dos o tres expresiones". Sin embargo, luego se retractó y negó la autorización que ya había otorgado, aunque, como sabemos, Ingenieros ignoró este cambio de parecer. ¿Cómo se explica este cambio de actitud? La respuesta está en una carta que Groussac le enviara a Ingenieros el 28 de enero de 1903. Lo que había sido una solicitud de permiso para publicar la carta del francés había cambiado de naturaleza. Lo que intentaba hacer $-\mathrm{y}$ logró, finalmente - Ingenieros era publicar, no una misiva del maestro que se había dignado a contestarle - aunque en su habitual tono ácido - a un posible discípulo, sino una polémica entre pares, contraponiendo sus respectivas opiniones en igualdad de condiciones. En realidad, Ingenieros se adjudicaba no solamente el derecho a quedarse con la "última palabra", sino además de definir el terreno en el que se desarrollaría el duelo escrito: su propia revista.

La publicación de una carta de Groussac como forma de obtener prestigio era también una forma implícita de sumisión al maestro. Sin embargo, una polémica entre ambos era una intención de volver horizontal una relación que en principio no lo era. Ante este cambio de rumbo, Groussac señalaba: "ahora me manifiesta la intención de exhibirme en una discusión con Ud. sobre filología, y tengo el sentimiento de no poder aceptar tal actitud ni aprobar su proceder". ${ }^{56}$ En consecuencia, retiró la autorización a publicar su carta "en cualquier forma que sea". Dos días después Groussac enviaba otra misiva en la que directamente intimaba a Ingenieros a "poner punto final a este comercio epistolar". ${ }^{57}$ No contamos con las versiones finales de las respuestas de Ingenieros a estas cartas de Groussac. En el archivo personal del primero, sin embargo, existe el borrador de una respuesta a esta última carta de Groussac que resulta interesante tanto por lo que dice como por las enmiendas que introdujo el autor en correcciones manuscritas sucesivas. Cabe destacar que este intercambio ocurrió antes de la publicación de la polémica en Archivos. Ingenieros terminaba el borrador diciendo que "su artículo será, pues, seguido 70-74.

56 Carta de Groussac a Ingenieros del 28 de enero de 1903, en Archivo Ingenieros, CEDINCI, A.6.1 SAA/8.4/4.1 documento 73

57 Tarjeta de Groussac a Ingenieros fechada el 30 de enero de 1903, en Archivo Ingenieros, CEDINCI, A.6.1 SAA/8.4/4.1 documento 74 . 
de un breve comentario en disidencia. Espero que Ud. verá con placer le prefiera la investigación propia a la aceptación servil de su opinión". ${ }^{58}$

El borrador estaba dividido en cuatro puntos numerados. En el primero, Ingenieros puntualizaba que, al haber consentido en un primer momento a la publicación de su carta, "ella pertenece a la publicidad y en tal carácter su opinión es susceptible de discutirse". En el segundo punto, le aclaraba a Groussac que "no aparecerá Ud. discutiendo [subrayado en el original] conmigo sobre cuestiones filológicas [tachado: sé que en ese terreno no cabe discusión entre nosotros] sino, como ha sido realmente, consultado" [subrayado en el original]. Eso no obstaba, continuaba Ingenieros, para que éste se abstuviera a considerar la opinión del francés como definitiva. El tercer punto resulta todavía más significativo. Aquí Ingenieros anunciaba que había circulado la carta entre [tachado en el original: numerosos] colegas y amigos. En caso de no publicarla, estos colegas y amigos a los que no mencionaba "interpretarían el hecho como disconformidad de mi parte con el trato acídulo que Ud. me da [tachado: en cambio que ese detalle no me afecta, pues Ud. no sabe (o no puede) escribir en otro estilo].

En este punto podemos decir que lo que Ingenieros temía era que la discusión (más bien la proyección social de la misma) se desplazara del lugar donde él quería ubicarla y donde definitivamente se sentía más cómodo: el de una discusión científica basada en evidencia, y, en cambio, retornara al lugar donde Groussac parecía más interesado en posicionarla: uno en el que la desigualdad en lo que respecta a la posesión de autoridad y prestigio se pusiera en evidencia. En una confrontación de este tipo, Ingenieros sólo podía salir en posición disminuida. El joven médico no podía permitirse aparecer como intimidado por las ironías de quien, desde todo punto de vista, era su superior en la percepción social.

Finalmente, en el punto cuatro, Ingenieros señalaba que los alumnos de la Facultad de Medicina solían consultarlo sobre materias de su especialidad. Y concluía: "mi superioridad [tachado en el original: indiscutible] sobre ellos, no obsta para que alguno no acepte mis opiniones, lo que tengo en alta estimación por representar criterio propio en el alumno disidente". Ingenieros admitía que en este caso — es decir, la discusión sobre filología — "medie igual distancia entre nosotros [tachado: y le aseguro que no me guía la pretensión de salvarla tratándose de cuestiones filológicas] y espero que sepa estar a la altura de su indiscutida autoridad". De este modo, al tiempo que se ubicaba en una posición casi discipular, Ingenieros se sentía con derecho de impartir al maestro instrucciones acerca de cómo comportarse como tal con dignidad.

La carta terminaba con un argumento que Ingenieros repetiría en su refutación publicada a Groussac: en un principio había estado dispuesto a aceptar los argumentos del francés in verba magistri, "pero mis hábitos de

58 Borrador sin fecha, en Archivo Ingenieros, CEDINCI, A.6.2 SAA/8.4/9.1, documento 28. 
estudioso rebeláronse bien pronto contra esa voluntaria capitis diminutio". Si Ingenieros no podía competir con Groussac en términos de autoridad y prestigio, sí podía hacerlo desde la ciencia y la posesión de conocimientos especializados, es decir, en palabras de Groussac, precisamente desde "el laboratorio y la clínica".

Antes de retomar la versión publicada del intercambio, hay algunos puntos que interesa resaltar de esta correspondencia privada. En primer lugar, Groussac trataba de mantener la asimetría de la relación mientras Ingenieros parecía esforzado en diluirla. Groussac se negaba a aparecer discutiendo temas de su especialidad con un joven practicante de una disciplina que nada tenía que ver con la filología. Polígrafo, Groussac era tenido como una autoridad indiscutible en temas de filología, pero no en cuanto una especialidad científica, sino como parte de una cultura general más amplia. El intelectual francés corría un enorme riesgo de ver puesta en duda su erudición al entrar en una contienda de la cual, además, tenía pocas posibilidades de salir airoso. Y estas pocas posibilidades no se debían solamente al hecho de que Ingenieros pudiera o no refutar sus argumentos, sino a algo mucho más importante: era Ingenieros y no él, esta vez, quien imponía las reglas del juego, comenzando por el lugar de la publicación. No se trataba de La Biblioteca dirigida por Groussac, ni siquiera de un espacio neutral, sino de la revista que dirigía el propio Ingenieros y que estaba fuertemente asociada a su nombre lo que otorgaba, además, el derecho de quedarse con la última palabra.

Sin embargo, el control de las reglas de juego no se limitaba al lugar en que se publicaría la polémica, sino que incluían algo mucho más importante: una puesta en cuestión de los mecanismos de legitimación y jerarquías aceptados por el francés. Ingenieros refutaba a Groussac con sus propias armas: un análisis etimológico y filológico. La consulta de fuentes prestigiosas permitía a Ingenieros cuestionar las certezas del francés. Pero ocurre que Ingenieros accedió (según su versión) a fuentes mejores y más actualizadas que quien se suponía que era una autoridad indiscutible en el tema.

Resulta interesante mencionar que, en su primera misiva, Groussac señalaba irónicamente su extrañeza por el hecho que Ingenieros haya dejado "a la decisión de un aficionado su bautismo científico". Ingenieros aprovechó la oportunidad para reposicionar a Groussac (y a sí mismo) en la polémica. Groussac, sostenía Ingenieros, era sin duda un aficionado en lo que respecta a la psiquiatría "como está condenado a serlo", añadía: "quien no puede agregar al aprendizaje del bufete la sanción de la clínica y el laboratorio".

El bufete y el laboratorio: he aquí los dos polos de una tensión que Groussac quería resolver en favor del primero e Ingenieros del segundo. Groussac era, en palabras de Ingenieros, "un sacerdote". Se trataba - parafraseando al propio Groussac - de un "bautismo" y los bautismos, —respondía Ingenieros-, eran potestad de los sacerdotes, y al francés se lo tenía por uno en lo referido al lenguaje. Pero ocurría que el tiempo de los sacerdotes estaba llegando a 
su fin. "En nuestro siglo" continuaba Ingenieros, "se debe acudir al perito, al especialista, han terminado los tiempos en que los augures y las pitonisas a todo sabían responder con igual inexactitud". .59

Lo que en realidad estaba poniendo de manifiesto Ingenieros, era una reformulación de los criterios de legitimación del saber y de los mecanismos de acumulación del prestigio intelectual, reconvertible en distinción social; la carta de Ingenieros reflejaba y, a la vez, contribuía a una reformulación de las reglas de legitimación y consagración que estaba ocurriendo dentro del espacio intelectual. Las nuevas reglas, basadas en la posesión de conocimiento experto requerían, no solamente de la posesión de saberes especializados, sino además de todo un dispositivo de publicidad del mismo. Y si ello era así, volviendo al segundo punto, se producía una reformulación de los criterios de jerarquía social.

\section{Consideraciones FINALES}

Aunque el motivo aparente de la contienda entre Groussac e Ingenieros fue la definición trivial de un vocablo, lo que estaba en juego era en realidad mucho más importante. De alguna manera, el debate dejaba en evidencia el entramado de las dinámicas de un mundo cultural tensionado en diferentes tipos de prácticas, en el que convivían letrados y profesionales, polígrafos y expertos, diletantes y bohemios; en el que se superponían círculos de sociabilidad informales con cátedras, institutos y academias profesionales; en el que formas personalistas de definir lo aceptable y lo censurable comenzaban a perder terreno frente a espacios de difusión y creación de saberes con pautas respetadas colectivamente. Esta convivencia de elementos habilitaba la coexistencia de actores muy diferentes entre sí.

Dos textos de Ingenieros de mediados de la década de 1910 permiten percibir con claridad el cambio de clima que ya para ese entonces se había producido, así como las posiciones que, alrededor del Centenario, ocupaban los dos protagonistas de nuestra historia; muy diferente a la que habían tenido en 1903. Por un lado, en el prólogo a la nueva edición de Las neurosis de los hombres célebres que escribió Ingenieros en 1915, bajo el título "La personalidad intelectual de José María Ramos Mejía", al referirse a Groussac - caracterizado como "el docto crítico"- y a la decisión de Ramos Mejía de elegirlo para prologar la primera edición de su obra, dudaba de la idoneidad del francés para hacerlo, pero, al mismo tiempo, reconocía que, en el contexto de 1895, solicitar el prólogo del francés había sido una actitud esperable ante quien era considerado "un maestro". En el fondo, se percibe en este comentario la impresión de Ingenieros de que, lo que para 1895 había sido aceptable, ya no lo era en el mundo de mediados de 1910, cuando lo que se podía decir sobre

59 Ingenieros, "En disidencia con Groussac", p. 70. 
Ramos Mejía y su obra, gracias al desarrollo conocimientos expertos, era otra cosa y quedaba por fuera de las competencias de polígrafos como Groussac.

Por otro lado, en 1917, y en las páginas de la Revista de Filosofía, Ingenieros mostraba una actitud ambigua - aunque escondida en lo que parecía a primera vista una lluvia de elogios - al comentar la aparición de Mendoza y Garay de Groussac. Sobre él destacaba:

Su autor tiene, como pocos, derecho al bronce perenne. No es su menos mérito el de haber enseñado, con el ejemplo que es la única docencia eficaz, los métodos modernos de investigación y la aplicación aguda del espíritu crítico, aunque lo primero mejor que lo segundo, pues el método puede trasmitirse y el ingenio no. Sus víctimas - de un minuto, luego y con mayor sazón convertidas en admiradores suyos — han aprendido de él, lo mismo que sus adversarios; si aquellos han tenido que dolerse transitoriamente de algún agravio, estos han sido casi siempre jóvenes que han puesto su vanidad primeriza en inferírselo. ${ }^{60}$

Si en este pasaje parece haber una clara referencia a su propia experiencia en el debate de 1903, en 1917 Ingenieros ya se sentía en condiciones de hacer una evaluación del rol de Groussac en tiempo pasado, o, por lo menos, como una figura bisagra entre una vieja guardia y la de relevo:

Culmina el autor en la intersección de dos épocas de nuestra vida intelectual. Antes de Groussac y después de Groussac, todo ha sido distinto: las letras, las artes y las ciencias han sufrido una trasmutación total. Bastaría comparar a Obarrio con Bunge, a Andrade con Lugones, a Mitre con Levene, a Lafone con Outes, a Cambaceres con Larreta, a Muñíz con Hicken, a Gutiérrez con Gálvez, para advertir que hemos entrado a un mundo nuevo. ${ }^{61}$

En ese mundo de prácticas culturales más definidas, figuras como las del propio Groussac parecían ya no tener un espacio central, y si la revista que ahora dirigía Ingenieros $-\mathrm{y}$ su mismo director- se asociaron a homenajes realizados al intelectual francés en otras oportunidades, lo que se resaltaba del homenajeado era fundamentalmente sus críticas a la metafísica y a la religión o su entusiasmo por un socialismo reformista, temas caros a Ingenieros desde su juventud remota, y no tanto su posición dentro de un campo intelectual en pleno proceso de renovación. ${ }^{62}$ En el marco de esta nueva configuración del mundo intelectual, los pilares en los que el francés había basado su trayectoria fueron viéndose corroídos.

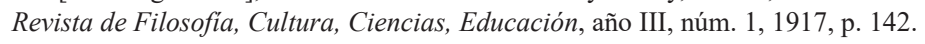
Revista de Filosofia, Cultura, Ciencias, Educación, año III, núm. 1, 1917, p. 142.

J.I. [José Ingenieros], "Paul Groussac: Mendoza y Garay, 1 vol., Buenos Aires, 1916",

${ }^{61} \quad$ Ibid., p. 143.

62 Véase por ejemplo, "Testamento filosófico" por Paul Groussac. Revista de Filosofía. Cultura, Ciencias, Educación, año V, núm. 4, 1919, pp. 171-176 y "Una demostración a Paul Groussac", Revista de Filosofía. Cultura, Ciencias, Educación, año VI, núm. 1, 1920, pp. $65-79$ 
Este proceso de renovación ya se vislumbraba en tiempos de la polémica de 1903. Y es por esto que Ingenieros — volviendo a la misma-, luego de reconocer amablemente su inferioridad respecto de Groussac, terminaba dándole lecciones de ética profesional y científica. ¿Se trataba de un mero juego retórico?, tal vez, pero preferimos avanzar la hipótesis de que Ingenieros era honesto tanto cuando proclamaba la asimetría que definía su relación con Groussac como cuando se permitía indicarle a éste las reglas de la etiqueta científica, es decir, las reglas de la modernidad. Si Groussac pretendía no quedar relegado al desván de la historia ("al bronce", como Ingenieros proclamaría una década más tarde), entonces debía comportarse como un especialista, es decir, como lo hacía el propio Ingenieros con sus alumnos, llevando el nivel de la discusión al de la evidencia científica y aceptando disidencias con sus propios puntos de vista; es decir, privilegiando el laboratorio sobre el bufete. Si Ingenieros, el siciliano, se atrevía a discutir de igual a igual con el príncipe de los intelectuales que además corría con una enorme ventaja derivada de su prestigioso origen nacional, era porque lo que estaba en proceso era una redefinición (para la cual Ingenieros mismo fue instrumental) de las jerarquías sociales y de la constitución de la naturaleza misma de los roles intelectuales que se ponían en juego en este "momento fuerte".

\section{Bibliografía}

Bagú, Sergio, Vida ejemplar de José Ingenieros, Buenos Aires, El Ateneo, 1953.

Bourdieu, Piere, "L'illusion biographique", en Bourdieu, Raisons pratiques, Sur la théorie de l'action, Paris, Éditions du Seuil, 1994, pp. 81-89.

Bruno, Paula, "Paul Groussac y La Biblioteca (1896-1898)", Hispamérica. Revista de literatura, año 32, núm. 94, 2003, pp. 87-94.

, Paul Groussac. Un estratega intelectual, Buenos Aires, Fondo de Cultura Económica, 2005.

(ed.), Travesías intelectuales de Paul Groussac, Bernal, Universidad Nacional de Quilmes, 2004.

_ _ "La vida letrada porteña entre 1860 y el fin-de-siglo. Coordenadas para un mapa de la elite intelectual”, Anuario IEHS, núm. 24, 2009, pp. 338-369.

—., Pioneros culturales de la Argentina. Biografías de una época, 1860-1910, Buenos Aires, Siglo XXI Editores, 2011.

(dir.), Sociabilidades y vida cultural. Buenos Aires, 1860-1930, Bernal, Universidad Nacional de Quilmes, 2014.

"Biografía e historia de los intelectuales. Balance y reflexiones sobre la vida cultural argentina entre 1860 y 1910”, Literatura y Lingüística, núm. 36, 2017 , pp. 19-36.

Canter, Juan, Contribución a la bibliografía de Paul Groussac, Buenos Aires, El Ateneo, 1930.

Darío, Rubén, “El triunfo del Calibán”, El Tiempo, 20 de mayo de 1898. 
Ginzburg, Carlo, “Apéndice. Pruebas y posibilidades”, en Ginzburg. El hilo y las huellas. Lo verdadero, lo falso, lo ficticio, Buenos Aires, Fondo de Cultura Económica, 2010.

Geertz, Clifford, "La descripción densa: hacia una teoría interpretativa de la cultura". en Geertz, La interpretación de las culturas, Barcelona, Gedisa, 1992, pp. 19-40.

González Bernaldo de Quirós, Pilar, Civilidad y política en los orígenes de la Nación Argentina. Las sociabilidades en Buenos Aires, 1829-1862, Buenos Aires, Fondo de Cultura Económica, 1999.

Gramasci, Antonio, Gli intellettuali e l'organizzazione della cultura, Torino, Einaudi, 1966.

Groussac, Paul, "La degeneración hereditaria”, prólogo a José María Ramos Mejía, La locura en la historia, Buenos Aires, Félix Lajouane Editor, 1895.

, "La Asociación de Mayo y el Dogma Socialista", La Biblioteca, año II, tomo IV (1897), pp. 262-297.

, “Alphonse Daudet”, La Biblioteca, tomo VI (1897). Reproducido en Bruno (ed.) Travesías intelectuales de Paul Groussac, 2004, p. 272.

, "La desaparición de La Biblioteca", en La Biblioteca, tomo VIII, 1898, pp. 244-248.

, "A propósito de americanismos", Anales de la Biblioteca, tomo I (1900). Reproducido en Paul Groussac, El viaje intelectual. Impresiones de naturaleza y arte. Primera Serie, Madrid, Librería General de Victoriano Suárez, 1904, pp. 383-426.

, Santiago de Liniers, conde de Buenos Aires, 1753-1810, Buenos Aires, Arnoldo Moen y Hermano Editores, 1907.

, Crítica literaria, Buenos Aires, Jesús Menéndez e hijos, 1924.

Hackstaff, Karla, Feiwel Kupferberg y Catherine Negroni, Biography and Turning Points in Europe and America, Bristol, Policy Press, 2012.

Ingenieros, José, "Pablo Groussac y el Socialismo", La Montaña, año I, núm. 6, 15 de junio de 1897. Reproducido en La Montaña. Periódico socialista revolucionario (1897). Dirigido por José Ingenieros y Leopoldo Lugones, Bernal, Universidad Nacional del Quilmes, 1996, pp. 140-146.

—_ Simulación de la locura ante la sociología criminal y la clínica psiquiátrica, precedida por un estudio sobre la Simulación en la lucha por la vida en el orden biológico y social, Buenos Aires, s/e, 1903.

, "Paul Groussac: Mendoza y Garay, 1 vol., Buenos Aires, 1916", Revista de Filosofía, Cultura, Ciencias, Educación, año III, núm. 1, 1917, pp. 142.

, "Testamento filosófico" por Paul Groussac, Revista de Filosofía, Cultura, Ciencias, Educación, año V, núm. 4, 1919, pp. 171-176.

, "Una demostración a Paul Groussac", Revista de Filosofía. Cultura, Ciencias, Educación, año VI, núm. 1, 1919-1920, pp. 65-79.

Ingenieros, José y Paul Groussac, "Psiquiatro o psiquiatra. Absolviendo una consulta, por Paul Groussac" y "En disidencia con Groussac", Archivos de Criminología, Medicina Legal y Psiquiatría, vol. I, núm. 13, 1903, pp. 65-73.

Lappas, Alcibíades, La masonería argentina a través de sus hombres, Buenos Aires, Edición del autor, 1966.

Losada, Leandro, La alta sociedad en la Buenos Aires de la Belle Époque. Sociabilidad, estilos de vida e identidades, Buenos Aires, Siglo XXI Iberoamericana, 2008. 
Mollès, Dévrig, Triangle atlantique et triangle latin. L'Amérique Latine et le systèmemonde maçonnique (1717-1921), Université de Strasbourg, 2012.

Neiburg, Federico y Mariano Ben Plotkin (comps.), Intelectuales y expertos. La constitución del conocimiento social en Argentina, Buenos Aires, Paidós, 2004.

Oria, José, "La polémica de Menéndez y Pelayo con Groussac. Sobre el "Quijote" de Avellaneda", Humanidades, tomo XXIV, 1934, pp. 3-72.

Piglia, Ricardo, Respiración artificial, Barcelona, Planeta, 1980.

Pita González, Alexandra, La Unión Latinoamericana y el Boletín Renovación: Redes intelectuales y revistas culturales en la década de 1920, Colima-México, Colegio de México-Centro de Estudios Históricos de la Universidad de Colima, 2009.

Pita González, Alexandra y Paula Bruno, "Definiendo su propia emoción. Una lectura de El hombre mediocre de José Ingenieros", Estrategias del pensar. Ensayo y prosa de ideas en América Latina. Siglo XX, Liliana Weinberg (coord.), México, Universidad Nacional Autónoma de México, 2009, pp. 189-229.

Plotkin, Mariano, "José Ingenieros, El Hombre Mediocre, and the Possibilities and limits of Social Integration in Turn of the Century Argentina", Oxford Research Encyclopedia of Latin American History, 2016, William Beezley (ed.), Disponible en:

$<$ http://latinamericanhistory.oxfordre.com/view/10.1093/acrefore/

9780199366439.001.0001/acrefore-9780199366439-e-346?rskey= F5Xsiz\&result $=5>$.

Plotkin, Mariano Ben y Eduardo Zimmermann (comps.), Los saberes de Estado, Buenos Aires, Edhasa, 2012. , Las prácticas del Estado, Buenos Aires, Edhasa, 2012.

Ponce, Aníbal, José Ingenieros: su vida y su obra. Educación y lucha de clases, Buenos Aires, J. Héctor Matera, 1953.

Terán, Oscar, José Ingenieros, antiimperialismo y nación, México, Siglo XXI, 1979. - José Ingenieros, pensar la nación, Buenos Aires, Alianza, 1986.

- Vida intelectual en Buenos Aires fin-de-siglo. Derivas de la cultura científica, Buenos Aires, Fondo de Cultura Económica, 2000. 